\title{
O SILÊNCIO GERADOR DE EFEITOS JURÍDICOS: uma análise de direito privado
}

\author{
Dissertação de mestrado \\ Orientador: Professor Associado Alessandro Hirata
}

UNIVERSIDADE DE SÃO PAULO

FACULDADE DE DIREITO

São Paulo-SP 


\title{
O SILÊNCIO GERADOR DE EFEITOS JURÍDICOS: uma análise de Direito Privado
}

\author{
Dissertação apresentada à Banca Examinadora do \\ Programa de Pós-Graduação em Direito, da Faculdade \\ de Direito da Universidade de São Paulo, como \\ exigência parcial para a obtenção do título de Mestre em \\ Direito, na área de concentração do Direito Civil, sob a \\ orientação do Professor Associado Alessandro Hirata.
}

UNIVERSIDADE DE SÃO PAULO

FACULDADE DE DIREITO

São Paulo 
Catalogação da Publicação

Serviço de Biblioteca e Documentação

Faculdade de Direito da Universidade de São Paulo

Tronco, Arthur Abbade

o silêncio gerador de efeitos jurídicos: uma

análise de direito privado / Arthur Abbade Tronco ; orientador Alessandro Hirata -- São Paulo, 2017.

$166 \mathrm{p}$.

Dissertação (Mestrado - Programa de Pós-Graduação em Direito Civil) - Faculdade de Direito, Universidade de são Paulo, 2017.

1. Direito civil. 2. Silêncio. 3. Fato jurídico. 4. Exteriorização de vontade. 5. Boa-fé. I. Hirata, Alessandro, orient. II. Título. 


\section{Agradecimentos}

Em primeiro lugar, agradeço ao Prof. Alessandro Hirata pela orientação durante essa empreitada de aprofundamento no universo acadêmico.

Agradeço, também, à Faculdade de Direito do Largo de São Francisco, especificamente, e à Universidade de São Paulo, de uma forma mais abrangente, instituições de ensino que me acolheram - o que faço na pessoa de seus Professores, os quais enriqueceram em muito meu processo de aprendizado, durante a pesquisa de mestrado.

Sou grato, ainda, às e aos colegas de pós-graduação, companheiras e companheiros de jornada, bem como às amigas e aos amigos, de dentro ou mesmo de fora da área do direito, que me ajudaram, com eventuais conversas sobre meu tema de estudo, a formular conceitos e clarear ideias e, principalmente, a abstrair um pouco, sempre que necessário, deste profundo e profuso mar de conhecimento que é o direito.

E, por fim, meu "muito obrigado" à minha família, que sempre me oferece todo o suporte necessário nessas longas caminhadas, com total confiança nos resultados delas advindos - com toda certeza muito maior do que aquela que eu mesmo tenho e que me faz ver o valor de tanto esforço. 
Un soupir,

Un régard,

Une simple rougeur...

Un silence est assez pour expliquer un coeur.

("Dom Garcie de Navarre", Molière) 
Arthur Abbade Tronco. O silêncio gerador de efeitos jurídicos: uma análise de direito privado. 2017. 166 páginas. Mestrado - Faculdade de Direito, Universidade de São Paulo, São Paulo, 2017.

O presente trabalho tem por principal alvo o estudo do silêncio na condição de instituto jurídico, isto é, como uma figura, reconhecida pelo direito como apta a - em determinadas hipóteses - produzir efeitos jurídicos. Tal análise, contudo, restringir-se-á à seara privada do direito, com especial foco no ramo do direito civil, dado que impossível pretender abarcar a ciência jurídica como um todo. A fim de concretizar os objetivos visados, esta dissertação apresenta aos seus leitores o seguinte roteiro. De saída, como não poderia deixar de ser, tem lugar uma breve apresentação tanto do trabalho quanto do tema. Ou seja, mostra-se ao leitor, mais detidamente, as motivações atinentes à pesquisa realizada, bem como a metodologia nela empregada e - já com vistas à introdução, efetivamente, no objeto de estudo - passa-se a uma contextualização da temática do silêncio dentro do grande campo do direito civil, em meio ao qual terá desenvolvimento todo o trabalho. Feito isso, há espaço para uma, igualmente breve, introdução histórico do tema, por meio da análise do silêncio no direito romano - em grande medida, berço de nosso direito civil atual. Ultrapassadas essas etapas, torna-se possível um mergulho mais profundo no assunto do silêncio nos dias de hoje. Dedicam-se, então, três capítulos ao estudo das principais teses atualmente existentes, defendidas por autores nacionais e estrangeiros, que visam a explicar a figura jurídica do silêncio, discorrendo acerca de qual seja a sua natureza jurídica, da regulamentação que the confere os ordenamentos jurídicos e, sobretudo, do porquê da sua aptidão ou não à produção de efeitos jurídicos. Dissecadas essas teorias, afasta-se aquelas que se mostram equivocadas ou insuficientes, para adotar, como base explicativa do fenômeno do silêncio gerador de efeitos jurídicos, a teoria do fato jurídico - que, no Brasil, encontra dois grandes expoentes: Pontes de Miranda e Marcos Bernardes de Mello. Finalmente, a partir da adoção desse ponto de vista, este trabalho dá início a um momento mais concreto, promovendo, em primeiro lugar, o estudo de casos (citados pela doutrina ou mesmo suscitado pelos próprios diplomas legais) e, na sequência, uma análise jurisprudencial - direcionada ao Superior Tribunal de Justiça e a três tribunais de justiça estaduais. E, assim, com todo esse material - teórico e concreto - em mãos, finda-se essa dissertação com algumas palavras de fechamento, que pretendem apresentar as principais conclusões a que se chega a respeito do silêncio gerador de efeitos jurídicos. 
Arthur Abbade Tronco. Silence as a source of legal effects: an analysis of private law. 2017. 166 pages. Master - Faculty of Law, University of São Paulo, São Paulo, 2017.

The objective of this thesis is to analyze the cases in which the Law authorizes silence to produce legal effects. This thesis focuses on private law; as a broader scope would be render the analysis impossible. The introduction of this thesis is structured as follows: (i) we begin by presenting the subject matter and the rationale for this research, (ii) we will discuss the methodology used, and, (iii) we will show how the subject matter of silence fits within the wider context of Brazilian Private Law. Following the introduction, we will pass to a brief historical analysis, focusing on the treatment dispensed by the ancient Romans as to the subject matter of silence. We understand that this is necessary, as Roman law is, undeniably, the origin of civil-law tradition of contemporary private law. Following this historical examination, we will examine the subject matter of silence from a contemporary perspective. Three chapters are dedicated to the examination of theories concerning the legal effects of silence, its legal nature, and how the Law disciplines it. Following this presentation of key theories, we will select the theory that best suits the purposes of study our: the theory of the legal fact, as conceived by Pontes de Miranda and Marcos Bernardes de Mello. Based on the ideas of these authors, we will conduct an analysis of hypothetical and concrete cases in which silence has played a key role. Hypothetical cases were chosen from books and are, therefore, fictional. However, more important are the precedents from Brazilian courts, including the Brazilian Superior Tribunal de Justiça (the Brazilian Superior Court of Justice, which sits below the Brazilian Supreme Court) and three higher state courts. Following this exhaustive analysis of theoretical and concrete aspects, to conclude this thesis, we present our main findings and closing remarks. 


\section{SUMÁRIO}

Capítulo 1 - Introdução

Capítulo 2 - Silêncio no direito romano.

$\begin{array}{ll}\text { Capítulo } 3 \text { - Silêncio e dever de resposta } & 15\end{array}$

$\begin{array}{ll}3.1 \text { Natureza jurídica do silêncio } & 17\end{array}$

3.2 Natureza e fonte do dever de resposta 20

3.3 Crítica à teoria do dever de resposta 25

Capítulo 4 - Silêncio e boa-fé objetiva $\quad 30$

4.1 Silêncio como abuso de direito 33

4.2 Silêncio como venire contra factum proprium. E o fenômeno da suppressiosurrectio

Capítulo 5 - Silêncio e a teoria do fato jurídico $\quad 41$

5.1 Silêncio exteriorização de vontade 48

5.1.1 Silêncio como elemento de existência e requisito de validade 51

5.1.2 Silêncio circunstanciado $\quad 55$

$\begin{array}{ll}5.2 \text { Silêncio ausência de vontade } & 70\end{array}$

$\begin{array}{ll}5.3 \text { Classificação do silêncio } & 75\end{array}$

Capítulo 6 - Questões concretas envolvendo o silêncio 79

6.1 Recondução tácita da locação $\quad 79$

$\begin{array}{ll}6.2 \text { Aceitação tácita de herança } & 82\end{array}$

$\begin{array}{ll}6.3 \text { Esbulho da posse } & 85\end{array}$

6.4 Silêncio de representante presente a celebração de negócio jurídico por relativamente incapaz

6.5 Outros casos 90

6.5.1 Compra e venda a contento 91

6.5.2 Aprovação da execução ou inexecução do mandato 95

6.5.3 Ratificação do negócio representativo 97

Capítulo 7 - Análise jurisprudencial $\quad 101$

$\begin{array}{ll}7.1 \text { Superior Tribunal de Justiça } & 103\end{array}$

$\begin{array}{ll}7.2 \text { Tribunais de Justiça } & 109\end{array}$

7.2.1 Tribunal de Justiça de São Paulo $\quad 109$

7.2.2 Tribunal de Justiça do Rio Grande do Sul 126

7.2.3 Tribunal de Justiça de Pernambuco 139

7.3 Análise dos resultados 145

$\begin{array}{ll}\text { Capítulo } 8 \text { - Conclusão } & 149\end{array}$

$\begin{array}{ll}\text { Referências } & 160\end{array}$ 


\section{CAPÍTULO 1 \\ INTRODUÇÃO' ${ }^{1}$}

O silêncio é um tema apaixonante e as mais diversas formas de arte e de ciência a ele se dedicam. Afinal, o silêncio é intrigante, e o ser humano, curioso.

$\mathrm{Na}$ área da ciência jurídica não poderia ser diferente e, de fato, não é. O silêncio, como figura jurídica, é tema bastante controverso e afeito aos diversos ramos do direito. É matéria de direito público: desde o direito constitucional ${ }^{2}$ e processual (civil e penal ${ }^{3}$ ) quando pensamos, por exemplo, no direito fundamental de permanecer calado e não produzir prova contra si mesmo - até o direito administrativo ${ }^{4}$, no que diz respeito à celebração de contratos públicos, passando por outros ramos do direito, dito, público. Mas, mais importante - porque é aquilo de que aqui iremos tratar -, o silêncio é, igualmente, de grande relevo para o direito privado 5 .

Essa grandeza e pluralidade do silêncio permite perceber a importância de seu estudo, ao mesmo tempo que demonstra a dificuldade de trabalhá-lo, em razão do risco de se perder em meio a tantas e tão variadas abordagens possíveis e problemáticas existentes.

Tendo isso em vista, mostra-se ser da maior importância uma apropriada e bem definida delimitação do tema de estudo, a qual pretendemos neste capítulo introdutório realizar.

De saída - e aqui aproveitamos para explicar o subtítulo do presente trabalho -, importante ter sempre em mente que nossa pretensão é a de realizar uma análise do silêncio

\footnotetext{
${ }^{1}$ As citações e referência bibliográficas realizadas no presente trabalho - ao longo de seu corpo, em nota de rodapé ou ao final - seguem as diretrizes apontadas pelo Prof. Eduardo C. Silveira Marchi, em sua obra Guia de metodologia jurídica: teses, monografias e artigos, $2^{\mathrm{a}}$ ed., São Paulo, Saraiva, 2009.

${ }^{2}$ A. de MORAES, Direito ao silêncio e comissões parlamentares de inquérito, in Revista dos Tribunais, v. 93, n. 822, São Paulo, abr. 2004, pp. 496-511; J. C. COUCEIRO, A garantia constitucional do direito ao silêncio, São Paulo, Revista dos Tribunais, 2004.

${ }^{3}$ M. C. C. S. GIMENES, Direito ao silêncio na prisão em flagrante, in Processo penal e democracia: estudos em homenagem aos 20 anos da Constituição da República de 1988, coords. D. Malan e G. Prado, Rio de Janeiro, Lumen Juris, 2009, pp. 423-453.

${ }^{4}$ A. SADDY, Silêncio administrativo no direito brasileiro, Rio de Janeiro, Forense, 2014.

${ }^{5}$ M. M. SERPA LOPES, O silêncio como manifestação de vontade: obrigações em geral, Rio de Janeiro, 1935; R. Popesco-RAmniceano, Le Silence Créateur d'Obligations et l'Abus Du Droit, in Révue Trimestrielle de Droit Civil, t. XXIX, 1930, pp. 999-1009; P. BonfANTE, Il Silenzio nella Conclusione dei Contratti, in Rivista de Diritto Commerciale, v. IV, parte II, 1906, pp. 222-230.
} 
enquanto matéria do direito privado. Isto é, ficam excluídas as temáticas referentes ao silêncio no que concerne ao direito material público e também aos direitos processuais, a fim de que possamos nos focar e aprofundar nas questões de direito material privado (notadamente direito civil, mas também direito comercial - que serão merecedores, em matéria de silêncio, de igual tratamento).

É nossa intenção, portanto, analisar quais são os efeitos que podem decorrer do silêncio na esfera do direito privado, bem como buscar compreender o porquê da ocorrência dos mesmos. E a análise da produção desses efeitos jurídicos passa, a nosso ver, por entender qual a real natureza jurídica do silêncio, nas diferentes hipóteses em que se apresenta. Em outras palavras, o objetivo é responder: o silêncio é ou, ao menos, pode ser exteriorização de vontade? Se sim, de que tipo? Ou: quando não for vontade, o que será?

Assim, na presente pesquisa, procederemos à análise das diferentes teorias propostas pelos autores, nacionais e estrangeiros, que já tenham se aventurado no estudo e desenvolvimento do tema, a fim de buscar definir um posicionamento próprio, que permita a construção de uma teoria sólida, coesa e coerente acerca do silêncio na sistemática do direito privado.

As dificuldades são muitas; sobretudo, tendo em vista a característica do tema, historicamente pouco afeito a regras gerais, sendo, ao contrário, muito dependente da casuística. Cientes disso, mas acreditando também na importância da doutrina na construção de teorias jurídicas capazes de definir e conceituar institutos jurídicos, buscaremos trabalhar algumas das hipóteses dos casos concretos, em prol da construção e fortalecimento de uma ideia, tanto genérica e abrangente quanto possível, do silêncio no direito privado.

De grande valia será, ainda, a apresentação e análise de alguns julgados nacionais, de modo a verificar, empiricamente, de que maneira a Jurisprudência vem trabalhando -ou deixando de trabalhar - os conceitos elaborados pela doutrina. Assim, a partir de uma já sólida teoria proposta com relação ao valor e natureza jurídica do silêncio, poderemos tecer críticas, ou elogios, ao modo como os Tribunais de nosso país vem tratando a matéria.

Finalmente, como conclusão, não deixaremos de apresentar alguns apontamentos, com um resumo das principais ideias a que tivermos chegado. 
Antes, porém, de mergulharmos a fundo na questão do silêncio, acreditamos ser de extrema valia realizar uma breve contextualização temática do mesmo. Já tivemos a oportunidade, no item anterior, de explicitar a delimitação idealizada, qual seja, a determinação da natureza jurídica e valor do silêncio em matéria de direito privado.

Nessa seara, a discussão central carreada pela doutrina diz respeito à possibilidade, ou não, de o silêncio exteriorizar vontade. Neste estudo, também nós essa questão: se o silêncio pode apresentar esse caráter volitivo; e, se sim, em quais hipóteses. Porém, estudaremos, igualmente, o que ocorre - em termos jurídicos - com o silêncio dito avolitivo, isto é, que não traz em si um conteúdo de vontade. Nesse caso, a pergunta que se põe é se ele produzirá também efeitos para o Direito. Se afirmativa a resposta, cumpre desvendar como e por qual razão isso se dá. Isto é, de que maneira o ordenamento jurídico trata e qualifica esse silêncio sem vontade, de modo que também ele produz efeitos jurídicos.

Em primeiro lugar, com relação ao silêncio volitivo, há que se ter em mente que o atual ordenamento jurídico brasileiro prevê variadas formas pelas quais a vontade pode ser exteriorizada: desde as formas verbais, oral ou escrita, passando igualmente pelos gestos, como acenos com a cabeça ou as mãos, e pelos comportamentos, mas também, segundo alguns autores ${ }^{6}$, pelo silêncio.

Esta afirmação, contudo, não é pacífica. De fato, parcela da doutrina ${ }^{7}$ enxerga a possibilidade de que o silêncio, nos casos em que se verifiquem determinadas circunstâncias, seja um veículo de exteriorização da vontade. É comum ver os autores que defendem tal tese se referirem a estes casos como hipóteses de silêncio circunstanciado. Ou seja, hipóteses em que não há meramente o silêncio, mas um conjunto de fatores que o rodeia, tornando possível, portanto, extrair dele a vontade do sujeito silente.

\footnotetext{
${ }^{6}$ W. FLume, Rechtsgeschäft, 1992, trad. esp. J. M. M. González e E. G. Calle, El negocio jurídico, Madri, Fundación Cultural del Notariado, 1998, p. 92; R. LOTUFO, Código Civil comentado-parte geral (arts. $1^{\circ} a$ 232 - v.1), $2^{\mathrm{a}}$ ed., São Paulo, Saraiva, 2004, p. 302.

${ }^{7}$ G. GiORGI, Teoria delle Obbligazioni nel diritto moderno italiano, vol. 3, 7 a ed., Firenze, Fratelli Cammelli, 1907; F. LAURENT, Cours Élémentaire de Droit Civil, 4 vols., Bruxelas, Bruylant-Christophe, 1887; SERPA LOPES, O silêncio como manifestação de vontade, cit.; L. S. C. de MonCADA, Lições de Direito Civil: parte geral, v. 2, Coimbra, Atlantida, 1932.
} 
Entretanto, em um outro sentido, há autores ${ }^{8}$ que defendem a impossibilidade do enquadramento do silêncio como vontade. Esses explicam a produção de efeitos jurídicos do silêncio, a partir da tese da existência, em determinadas hipóteses, de um dever de falar, de um dever de manifestação daquele que se manteve calado. Seria, então, a não observância deste dever que teria por consequência a produção de efeitos jurídicos.

Essas e outras teorias - como por exemplo aquelas que visam a explicar a produção de efeitos jurídicos pelo silêncio avolitivo -, obviamente, necessitam de uma explicação muito mais detalhada. Entretanto, nos capítulos seguintes teremos a oportunidade de desenvolvê-las em muito maior profundidade, sendo nosso objetivo, por ora, apenas o de resumidamente introduzi-las ao leitor, a fim de que este vá se familiarizando com essas questões.

O que se afigura crucial nessa introdução e apresentação do tema é o esclarecimento da confusão que se faz, muitas vezes, em relação àquilo que se possa efetiva e juridicamente denominar de "silêncio" - a fim de que fique realmente claro qual será nosso objeto de estudo.

Diversos casos há em que a parte, pelo simples fato de nenhuma palavra proferir, é tida como silente, quando em verdade uma conduta ativa sua fora responsável pela produção de efeitos jurídicos - tenha havido ou não vontade nessa conduta.

Nesse sentido, buscando se afastar desta confusão, D. B. de O. ANDRADE ${ }^{9}$, afirma que o silêncio, enquanto figura jurídica, somente se caracteriza quando houver completa abstenção da parte: de palavras e de atos.

De maneira semelhante, PINTO ${ }^{10}$ fala em silêncio como inércia, que se estende a um nada fazer, para além do nada dizer. Ou ainda, nas palavras de BONFANTE ${ }^{11}$, seria o silêncio, em resumo, a inação absoluta.

\footnotetext{
8 J. de O. Ascensão, Direito civil: teoria geral, Coimbra, Coimbra; Bonfante, Il Silenzio cit;; Flume, Rechtsgeschäft cit.; P. C. C. da M. PINTO, Declaração tácita e comportamento concludente no negócio jurídico, Coimbra, Almedina, 1995.

${ }^{9}$ Do contrato: teoria geral, 4. ${ }^{a}$ ed., São Paulo, Saraiva, 1997, p. 118.

${ }^{10}$ Declaração tácita cit., p. 631.

${ }^{11}$ Instituzioni di diritto romano, 10. ${ }^{\mathrm{a}}$ ed., Torino, G. Giappichelli, 1946, p. 76.
} 
Estes autores estão corretos na ênfase colocada na ausência de palavras e de ações. Reforço para que fique claro. Não é, em primeiro lugar, a simples ausência de palavras que caracteriza o silêncio. Esse silêncio da mera falta de palavras, de sons, é o silêncio em sua acepção vulgar. O silêncio em sua acepção jurídica - que é aquele com o qual trabalharemos - é, menos um silêncio e, efetivamente, mais uma inação. Assim, para que se verifique real hipótese de silêncio, é preciso que não tenha havido um comportamento ativo da parte, do qual se possa extrair a justificativa da produção de determinados efeitos jurídicos. De acordo com a concepção que adotamos, só se constata o silêncio se determinado sujeito manteve-se inativo, isto é, se o indivíduo de qualquer forma não agiu.

Tão importante quanto o conceito exposto no parágrafo precedente é compreender que, em que pese ser ausência de palavras e ações, ao mesmo tempo, o silêncio não deixa de ser um comportamento humano, ainda que de caráter negativo. Podemos enxergar isso na assertiva de PINTO ${ }^{12}$, de que o significado específico e jurídico do termo silêncio seria um "comportamento totalmente omissivo". Assim, por mais que caracterizemos o silêncio como verdadeira inação, esta é, sim, um comportamento humano, não havendo aí incoerência.

Essa caracterização do silêncio como conduta humana é importante que seja bem compreendida, em razão das bases da teoria a ser desenvolvida na presente pesquisa, lastreada na teoria do fato jurídico, ou seja, no enquadramento do silêncio, em qualquer caso, como uma das espécies de fato jurídico.

Já nos encaminhando à conclusão desse capítulo introdutório, vale afastar a perigosa, porque falsa, ideia de que por ser um fato negativo - abstenção da fala e de ações - o silêncio seria sem relevância para o Direito. Afinal, o nada pode parecer irrelevante. Tal ideia, contudo, é equivocada. Essa inércia relativa ao silêncio importa, em diversas situações, consequências para o interesse dos sujeitos de direito, de modo que do silêncio não pode ser dito ser fato indiferente à sociedade ou ao ordenamento jurídico, merecendo, portanto, regulamentação por parte do direito ${ }^{13}$.

O que é preciso que se tenha muito claro, apenas, é que esses interesses decorrentes do silêncio, os efeitos dele advindos, em nada se relacionam ao adágio popular do "quem cala consente". Imperioso, em razão do nível de rigor e seriedade da ciência jurídica, afastar

\footnotetext{
${ }^{12}$ Declaração tácita cit., p. 631.

${ }^{13}$ B. de Mello, O silêncio no direito, in Revista dos Tribunais, São Paulo, a.26, v.105, jan 1937, p.4.
} 
tais raciocínios rasos. O ditado em questão, cuja origem remonta às regras do direito canônico - regra 43 do apêndice "De Regulis Iuris" do livro 5 do "Liber Sextus Decretalium" 14 - não pode servir de base à construção de uma séria teoria jurídica. Por vezes, competentes autores incorrem nesse equívoco, como M. Planiol, G. RIPERT, e P. ESMEIN ${ }^{15}$, quando comentam que determinada atitude abstencionista, em alguns casos, poderia ser considerada como consentimento por meio do brocardo em questão.

Veremos, no decorrer do trabalho, todas as razões pelas quais ora se caracteriza o silêncio como avolitivo, ora como volitivo, destrinchando o porquê de sua produção de efeitos no universo jurídico. Mas, obviamente, em nenhum momento essas questões se resolvem em razão da existência do ditado popular em questão.

${ }^{14}$ S. VALLAR, Silence et contrats en droit romain, in Révue des contrats, jul. 2014, p. 288.

${ }^{15}$ Traité pratique de droit civil français: obligations première partie, t. VI, 2a ed., Paris, LGDJ, 1952, p.116. 


\section{CAPÍTULO 8 \\ CONCLUSÃO}

Percorrido todo o percurso pretendido por essa pesquisa, chegamos à fase final e mais difícil, a nosso ver, de todo e qualquer trabalho acadêmico. Trata-se daquele momento em que se deve olhar para trás e realizar um balanço geral de tudo o que foi feito. É, em especial, a oportunidade de resumir as principais ideias alcançadas e também de parar e refletir sobre os resultados da pesquisa. Assim sendo, nesse derradeiro - e breve, pretende-se - capítulo, procederemos a essa árdua, tanto quanto prazerosa, tarefa de repisar os pontos mais marcantes desse trabalho, oferecendo nossas últimas conclusões a respeito do tema.

Antes de mais nada, vale dizer que, ao fim dessa empreitada acadêmica, dela saímos ainda mais convictos do acerto da escolha do tema do silêncio, cuja inegável relevância se estende pelas mais diversas áreas do Direito - tendo sido no presente trabalho, inevitavelmente, abarcado apenas diminuta parcela de suas questões, às quais, entretanto, se deu a devida atenção e profundidade na análise.

Como vimos - tendo sido, inclusive, destinado capítulo específico ao tratamento da matéria -, a figura do silêncio apresenta há tempos relevo em termos jurídicos. Era, já no direito romano, fonte de altas indagações e não poucas consultas aos juristas de então. Não obstante, pudemos observar a inexistência de um tratamento geral à matéria, o que talvez se explique também pela forma de desenvolvimento do direito romano (mais prática que teórica), mas principalmente pelas próprias características da temática.

É possível afirmar isso, pois até hoje não se pode dizer existir uma regra geral que explique extensivamente, ou exaustivamente, a questão do silêncio. Mesmo a existência de previsão legal expressa a esse respeito (artigo 111 do Código Civil) não tem o condão de exaurir todos os pormenores que advém de uma matéria tão complexa.

Foi em grande medida movido por esse desafio que essa pesquisa se iniciou e desenvolveu.

Em primeiro lugar, havia em nós a percepção de que a figura jurídica do silêncio tinha grande importância para o direito civil - matéria de nossa predileção -, sem receber, 
contudo, por parte da doutrina especializada a devida atenção. Em verdade, a situação é curiosa. Todo e qualquer autor passa, necessariamente, pela questão do silêncio ao tratar do direito civil, em razão da existência no próprio código de um dispositivo a ele dedicado, o que "impossibilita" que se passe ao largo do tema. Não obstante, no mais das vezes, são dedicada breves e rasas linhas a esse assunto em que poucos tiveram a coragem de mergulhar.

Assim, essa escassez de material de qualidade - algo sempre motivador à produção de obra de efetiva contribuição ao desenvolvimento do nosso direito - aliada à complexidade inerente ao tema foi combustível suficiente à propulsão de nossos estudos, os quais, como dissemos, se iniciaram e desenvolveram, na expectativa de disciplinar o silêncio, tanto quanto possível, de uma forma generalizada.

Não estamos falando na criação de uma regra geral ou fórmula mágica solucionadora das hipóteses envolvendo o silêncio - o que seria, claro, impossível. Pretendíamos, e esperamos ter conseguido, produzir um estudo teórico e genérico do silêncio que desse aos operadores do direito uma base mais sólida no momento de ter de enfrentar a sua casuística. Tudo isso com a pretensão de conferir maior tecnicidade na análise dos casos concretos relativos ao silêncio e, consequentemente, trazer mais segurança ao nosso ordenamento jurídico.

Afim de que tal intuito pudesse ser alcançado, interessante dizer que o próprio recorte do trabalho teve de sofrer uma alteração. Se ao projeto de pesquisa demos o título "O silêncio na celebração dos negócios jurídicos", não tardou a que percebêssemos que restringir a presente pesquisa ao estudo das hipóteses de silêncio envolvendo apenas negócios jurídicos não nos permitiria atingir os resultados desejados. Desse modo, esta dissertação, hoje, se apresenta intitulada "O silêncio gerador de efeitos jurídicos: uma análise de direito privado", a fim de que, logo de cara, note-se a pretensão globalizante do tema. Não ficamos, portanto, adstritos ao silêncio em sua relação com os negócios jurídicos, tendo analisado-o, igualmente, em um contexto referente a outros fatos jurídicos (ato-fato, ato jurídico).

Vale dizer, ainda com relação à evolução do tema, que ele se impôs à medida em que crescia o contato com as obras ao final referenciadas e cada uma das teorias propostas pelos autores estudados apresentava-se, a nosso ver, insatisfatória. Ora as ideias padeciam, realmente, de acerto; ora apenas não encontrávamos nelas o potencial conglobante desejado. 
Foi somente quando nos deparamos com a defesa da simples ideia da aplicação da teoria do fato jurídico ao silêncio que ficamos satisfeitos. A partir daí, no entanto, mostrou-se imprescindível que não estudássemos apenas o silêncio relativo a uma única espécie de fato jurídico (negócio jurídico), mas que, ao contrário, perquiríssemos a respeito de todas as espécies de fato jurídico em que o silêncio pudesse se enquadrar.

À luz dessa premissa - da necessidade, antes de mais nada, do enquadramento do silêncio em uma categoria de fato jurídico - desenvolveu-se o trabalho e algumas conclusões foram aparecendo.

A primeira delas talvez tenha sido a verificação de que nem todo silêncio tem caráter volitivo. Pesa a favor do chamado silêncio volitivo a previsão do artigo 111 do Código Civil, que fala em anuência (vontade). Percebemos, porém, que havia hipóteses em que, mesmo que não se pudesse cogitar de um elemento volitivo no silêncio, ele produzia efeitos jurídicos. Assim, a primeira medida tomada foi a de estruturar toda a sequência do trabalho e, de uma forma geral, todo o raciocínio diante de uma questão a envolver o silêncio, com base na diferenciação entre o silêncio exteriorizador ou não de vontade.

A esse respeito, inclusive, interessante notar que o tratamento dispensado pela doutrina a um e outro tipo de silêncio é absolutamente desequilibrado, sendo mais do que notório a prevalência da discussão do silêncio volitivo. Podemos suspeitar de uma série de razões para que assim seja. Uma delas talvez resida no próprio teor da previsão legal. Além disso, a própria dificuldade do tratamento da figura do silêncio avolitivo, a nosso ver ainda maior do que aquela atinente ao silêncio exteriorização de vontade, pode ser outro motivo. Em comparação, podemos dizer, com toda certeza, que é familiar à maioria dos autores a discussão da temática da vontade e de sua exteriorização, do ato jurídico em sentido estrito e do negócio jurídico. Por esse motivo, a inserção de um elemento extra - o silêncio - em discussão já mais amadurecida se mostraria, provavelmente, menos intimidadora.

Do silêncio sem vontade, ao contrário, o mesmo não se poderia dizer. Ora, o próprio nome, uma definição pela negação, dá mostras do porquê. Esta categoria apresenta conceito e natureza jurídica muito menos nítidos, porque pouco explorados. Desse modo, mostrou-se mais conveniente - ou, no mínimo, mais confortável - a sua denominação a partir da oposição ao outro gênero de silêncio. 
Em verdade, porém, a relação não é verdadeiramente de oposição. Isso porque, conforme dizíamos, valendo-nos da teoria do fato jurídico à explicação do silêncio, temos que ele, sempre que tiver valor jurídico, haverá de se enquadrar em uma das categorias de fato jurídico.

Assim, de um lado há o silêncio exteriorização de vontade conectado à categoria dos atos jurídicos lato sensu (ato jurídico em sentido estrito e negócio jurídico) e, de outro, o silêncio ausência de vontade como hipótese de ato-fato jurídico. E entre essas categorias não há real oposição, a qual se mostra, portanto, apenas aparente. Ato jurídico lato sensu e atofato jurídico são, simplesmente, espécies diferentes, por apresentarem características distintas - como se falássemos de elefantes e girafas.

Exatamente por apresentarem características diferentes, que os enquadram em categorias diferentes de fato jurídico, também o tratamento a ser dado pelo ordenamento jurídico ao silêncio volitivo ou avolitivo será diferente.

No que diz respeito ao silêncio avolitivo, por óbvio, não se cogita do elemento vontade, o qual é, recorrentemente, no Direito, alvo de controvérsias. Desta feita, ao menos nesse sentido, a análise é mais simples, pois não há necessidade de discussão dos subjetivismos afeitos às questões referentes à exteriorização de vontade.

Desse modo, se não é a vontade, isto é, se não é a autonomia privada que leva à produção de efeitos por parte do silêncio avolitivo, uma vez que nele ela está ausente, a única conclusão possível é a de que é o próprio comportamento silencioso e de inércia, objetivamente considerado, que gera os efeitos jurídicos.

Daí, justamente, a caracterização dessas hipóteses de silêncio como ato-fato jurídico, uma vez que se tratam de fatos geradores de efeitos jurídicos, portanto de fatos jurídicos, compostos por uma conduta humana (ainda que passiva, de ficar em silêncio) em que ausentes o elemento vontade ou em que tal elemento é desimportante - a definição dada pela doutrina para a categoria dos ato-fatos jurídicos.

Ainda a respeito do silêncio avolitivo, pertinente externar uma conclusão a seu respeito a que chegamos referente à figura da boa-fé objetiva. 
De início pouco explorada em nossa pesquisa, no decorrer do trabalho ficou claro que maior atenção precisava ser dada à boa-fé objetiva. Princípio recorrentemente invocado nas discussões do silêncio - em especial do silêncio não exteriorizador de vontade -, desempenha, muitas vezes, papel central na solução de controvérsias, conferindo juridicidade às explicações do porquê da produção de efeitos por um determinado silêncio sem vontade.

Assim, se a boa-fé objetiva não dava conta, em nosso entender, de desempenhar o papel de ser esse eixo generalizante em torno do qual todo o trabalho pudesse se estruturar, por outro lado, de rigor reconhecer nesse momento a crucial importância dessa figura ao bom andamento da pesquisa - sem o qual muitas perguntas que nos foram aparecendo ficariam, simplesmente, sem resposta.

Apenas a título ilustrativo, poderíamos citar a íntima relação existente entre o silêncio avolitivo caracterizado como ato-fato jurídico caducificante e as figuras derivadas da boa-fé objetivo da suppressio e da surrectio - tantas vezes explorada ao longo da presente pesquisa.

No que diz respeito, por sua vez, ao silêncio volitivo, a sua compreensão e explicação demandou percurso mais extenso, o qual resumidamente, agora, reapresentamos, uma vez que se trata, possivelmente, da principal conclusão, ou tese, do presente trabalho.

A primeira noção que se precisa ter muito clara é a de que o dito silêncio volitivo é, na verdade, a consideração do silêncio como um veículo para que a vontade seja exteriorizada. Assim como a vontade pode ser externalizada por meio de palavras escritas ou faladas, sons e gestos, ela também pode ser exteriorizada por meio de comportamentos e um desses comportamentos é o silêncio (não importando o fato de se tratar de um comportamento passivo, de inércia).

Tendo isso em vista, uma segunda ideia muito importante e que não pode ser confundida é a da vontade - ainda que exteriorizada - com a do ato jurídico em sentido amplo (ato jurídico em sentido estrito e negócio jurídico). É, infelizmente, comum ver na doutrina a conceituação do ato jurídico lato sensu e, mais especificamente, do negócio jurídico como sendo a vontade, numa relação de perfeita identidade, a qual, contudo, inexiste. 
Na realidade, a vontade (exteriorizada) é "elemento completante" do suporte fático de um ato jurídico. Em outras palavras, a vontade compõe o ato jurídico ela não é o ato jurídico, assim como o ato jurídico não é (apenas) a vontade. Assim, para que nasça um ato jurídico é preciso que a norma jurídica incida sobre uma conduta humana volitiva, mas também sobre os demais elementos por ela previstos como necessários à concretização do fato jurídico ${ }^{299}$.

Assim sendo, essencial sempre lembrar que o silêncio exteriorizador de vontade é elemento fático integrante de ato jurídico lato sensu, sem que se possa dizer, porém, que o silêncio é, em si, ato ou negócio jurídico.

Feita essas importantes considerações iniciais a respeito do silêncio volitivo, faz-se mister que procedamos, na sequência, à análise dos elementos essenciais dos atos jurídicos, a fim de que fique mais nítido o seu enquadramento ali.

A nosso ver, tanto em relação aos atos jurídicos em sentido estrito quanto no que concerne os negócios jurídicos, podemos considerar como havendo quatro elementos de existência e quatro requisitos de validade. Consideramos elementos de existência dos atos jurídicos: a) exteriorização de vontade; b) agente (emissor da vontade); c) objeto; d) forma. Já os requisitos de validade nada mais seriam do que a "adjetivação" desses elementos de existência: a) exteriorização de vontade livre e de boa-fé; b) agente (emissor da vontade) capaz e legitimado; c) objeto lícito, possível e determinado ou determinável; d) forma prescrita ou não defesa em lei.

Enxergamos o silêncio volitivo relacionado tanto aos elementos de existência e requisitos de validade relativos à vontade quanto aqueles referentes à forma.

Concerne à forma do ato jurídico por ser o silêncio um meio de exteriorização da vontade. Dessa forma, em atenção ao requisito de validade da forma prescrita ou não defesa em lei, o silêncio só poderá funcionar como veículo de exteriorização volitiva e, consequentemente, como elemento completante do núcleo do suporte fático de um ato jurídico se a lei não previr que a vontade deva ser exteriorizada de uma maneira específica (v.g.: documento público),

${ }^{299}$ Mello, Teoria cit., p. 171. 
Ainda mais importante é, claro, a análise do elemento de existência e requisito de validade relativos à vontade. A partir da conjugação das teorias do fato jurídico, dos elementos de existência e requisitos de validade dos atos jurídicos, bem como das ideias específicas desenvolvidas pela doutrina a respeito do silêncio volitivo, resumidamente, a conclusão a que chegamos é a de que será possível afirmar a existência de vontade válida no silêncio se presente no caso concreto um elemento que o qualifique nesse sentido. Trata-se da teoria do silêncio circunstanciado.

Grosso modo, de acordo com essa teoria, o silêncio poderá significar uma exteriorização de vontade (positiva ou negativa, isto é, de anuência ou de recusa), desde que se verifique no caso concreto elemento apto a qualifica-lo como volitivo. A nosso ver, os elementos que detém essa aptidão são: a) prévia convenção entre as partes; b) previsão legal; c) usos e costumes; d) circunstâncias do caso concreto.

De maneira bastante sucinta, a respeito da convenção prévia entre as partes, podemos dizer que qualifica o silêncio em razão dos ditames do princípio da autonomia privada. Não há a esse respeito muito mais a ser dito, sendo essa situação comumente aceita pela doutrina. Ora, se as partes previram um determinado significado ao silêncio, não atentando essa convenção contra a lei, será esse o significado que o silêncio terá, seja de anuência, seja de recusa.

A respeito da previsão legal, por sua vez, bastante se discute a respeito da existência de uma real vontade da parte silente, havendo autores ${ }^{300}$ que defendem não haver, em tais casos, senão uma "vontade legal", isto é, uma vontade criada pela lei. A nosso ver, contudo, entendemos não haver que se falar em criação da vontade pela lei, senão de uma interpretação ou, no máximo, valoração do silêncio pela lei como sendo este volitivo.

Em termos mais pragmáticos, porém, a verdade é que, em qualquer caso, sempre que a lei vier expressamente afirmar que determinada conduta silenciosa importa recusa ou anuência, estará reconhecendo caráter volitivo ao silêncio. E, assim, terão lugar as ordinárias consequências de uma “" exteriorização de vontade (como a formação ou não de um negócio jurídico, por exemplo).

${ }^{300}$ FLUME, Rechtsgeschäft cit., p.152 e AsCENÇão, Direito civil cit., p. 32. 
O que há de mais importante, a nosso ver, na lei como elemento qualificador do silêncio é a alta carga de segurança jurídica e isso é muito salutar. Essa mesma segurança, por sua vez, tem muito menor incidência no que se refere às circunstâncias e aos usos e costumes como qualificadores do silêncio - o que não significa dizer que não possamos a eles recorrer.

$\mathrm{Na}$ realidade, acerca dos usos e costumes, é preciso dizer, em primeiro lugar, que uma diferenciação é feita entre eles por parcela da doutrina. Entendem alguns autores ${ }^{301}$ que um costume surgiria de um uso, o qual após sucessivas e reiteradas práticas passaria a ser tido como algo obrigatório pela coletividade (norma consuetudinária). Assim, o uso apresentaria uma característica mais privada, mais particular e menos difundida, enquanto o costume teria caráter genérico e, inclusive, obrigatório.

Em que pese a diferenciação apresentada, à qual não nos opomos, parece-nos que tanto usos quanto costumes podem funcionar como elementos qualificadores do silêncio. A diferença apenas que talvez se vislumbre é uma relativa aproximação do costume, como qualificador do silêncio, da lei, uma vez que igualmente norma (ainda que consuetudinária), enquanto os usos, dada a sua natureza particular e específica se aproximariam mais das circunstâncias do caso concreto, como elementos qualificadores do silêncio.

Em todo caso, em razão de não haver um código de usos e costumes, inegavelmente, a sua falta de previsão expressa (ao contrário do que observado em relação aos dois primeiros elementos qualificadores do silêncio) leva a uma menor segurança jurídica em relação à qualificação do silêncio como exteriorização de vontade. E, assim, em surgindo dúvidas e conflitos a esse respeito, maior será a importância e participação, a nosso ver, do Poder Judiciário, na solução de tais conflitos. Isto é, em caso de alegação de uma das partes - e não aceitação pela outra - de um determinado valor ao silêncio em razão de um uso ou costume, invariavelmente, a resposta a essa controvérsia dependerá de um pronunciamento judicial.

O mesmo vale quando se pretende usar as circunstâncias do caso concreto para a qualificação do silêncio. Em verdade, as "circunstâncias" é elemento que não aparece na doutrina especializada que trata do silêncio exteriorizador de vontade, mas que achamos por bem incluir no rol de elementos qualificadores por dois principais motivos. O primeiro é a

${ }^{301}$ VenosA, Direito Civil cit., p. 15. 
sua expressa menção no texto do artigo 111 do Código Civil e o segundo é o fato de que, por vezes, o silêncio tem nítido caráter volitivo, produz efeitos jurídicos, mas não encontra qualificação nas outras figuras aqui apresentadas. Assim, as circunstâncias do caso concreto, a nosso ver, podem funcionar como mecanismo subsidiário de qualificação do silêncio. A consequência negativa dessa estratégia, contudo, é eventual redução de uma previsibilidade e, portanto da segurança jurídica, a qual cede, no entanto, frente à necessidade de flexibilidade do sistema. Em todo o caso, por todo o exposto, devem essas últimas hipóteses ser aplicada com cautela e parcimônia por quem pretender invoca-las, notadamente, pelo Poder Judiciário.

Como se vê, o próprio desenvolvimento da pesquisa foi ressaltando a importância da, já de antemão prevista, análise jurisprudencial do tema. Assim, findo o percurso de cunho eminentemente teórico, cuja pretensão era a de construção e solidificação de uma teoria ao silêncio - tanto volitivo quanto avolitivo, passamos à pesquisa de julgados relativos à temática.

Em capítulo próprio desenvolvemos esse estudo e apresentamos algumas de nossas conclusões. Cabe aqui apenas retomar alguns fatos que mais nos chamaram atenção.

Em primeiro lugar o fato de que houve praticamente o mesmo número de julgados em que o silêncio foi considerado como gerador de efeitos e não gerador de efeitos jurídicos. Quais conclusões podem ser inferidas desse dado? A nosso ver, ele demonstra que, de fato, a produção de efeitos jurídicos pelo silêncio tem caráter excepcional, pois mesmo em sede de Judiciário - âmbito em que já chegam apenas os casos eivados de controvérsia (e, portanto, de certa excepcionalidade) - apenas em metade dos casos foi reconhecido ao silêncio a aptidão à produção de efeitos jurídicos. Além disso, parece-nos que, justamente em razão do equilíbrio numérico de decisões em um e outro sentido, esse dado também dá mostras do efetivo alto grau de controvérsia atinente à matéria.

Para além disso, no entanto, fica um gosto amargo de frustração, que recorrentemente acomete àqueles que se propõe a tal tipo de estudo.

De um lado, restou frustrada a pretensão de que, a partir da análise jurisprudencial, pudesse ser esclarecida, ou exemplificada de maneira mais sólida, de que forma podem ser trabalhados os usos e as circunstâncias na qualificação do silêncio. Isso não foi possível fazer 
em razão da escassez de julgados que versassem acerca de um silêncio exteriorizador de vontade (cinco dentre vinte quatro julgados analisados).

Ao mesmo tempo, a frustração se explica pela falta de qualidade técnica das decisões. Os Tribunais, muitas vezes, sequer se dão conta de estarem diante de um caso de silêncio e se a isso se atentam, via de regra solucionam o caso considerando o silêncio como "anuência", mesmo que não se trate de silêncio volitivo. Isso se explica, nitidamente, em razão da única previsão expressa a respeito do silêncio no Código Civil (artigo 111), que fala em silêncio como anuência. Explica-se, mas não se justifica. Não se justifica que não se proceda à busca da efetiva natureza jurídica do silêncio como fato jurídico na situação concreta, a fim de conferir ao caso o mais adequado enquadramento jurídico e, consequentemente, a melhor solução.

A despeito disso, a análise jurisprudencial não se mostrou completamente desprovida de sentido, tendo surgido interessantes casos de silêncio, os quais deram margem a relevantes comentários e aplicações de nossas ideias a respeito do silêncio.

Isso funcionou também, a nosso ver, como verdadeira "prova de fogo" da teoria aqui defendida. Tendo sido possível, com maior ou menor dificuldade a depender do caso concreto, analisa-los todos com base nos preceitos aqui trabalhados, fica a sensação de que estes se apresentam providos de razoável substância e solidez.

Dito isso, a nossa esperança é a de que a presente pesquisa tenha atingido o seu objetivo de clarificar, ao menos um pouco, este controverso tema. Afinal, efetivamente acreditamos que, adotando como uma espécie de ponto de partida a teoria do fato jurídico na análise do silêncio, todo o subsequente trabalho de compreensão e interpretação das hipóteses de silêncio e seus efeitos decorrentes fica muitíssimo mais simples.

Vale dizer que a precisa aplicação da teoria do fato jurídico faz com que pouco se precise inovar para se atingir uma adequada teoria explicativa do silêncio, sendo no máximo necessário que se voltem os olhos à teoria do silêncio circunstanciado, em se tratando de silêncio exteriorização de vontade. Teoria essa, porém, que se mostra bastante sólida e em prol da qual buscamos ao longo do trabalho argumentar.

Essa foi também uma de nossas preocupações e que, esperamos, tenha recebido deslinde bem-sucedido. Deparamo-nos como uma confusa profusão de teorias que se 
propunham a explicar a juridicidade do silêncio. Assim, muito mais do que propor teoria pretensamente inovadora, nosso objetivo era o de, nos valendo daquilo que já encontramos edificado, organizar as ideias - muitas vezes apenas aparentemente incompatíveis -, tentando de alguma forma pacificar a questão. Buscamos, portanto, a construção de uma teoria do silêncio, tanto ampla quanto possível, baseada em uma teoria outra que nos podia oferecer das mais sólidas fundações: a teoria do fato jurídico.

E assim esperamos ter colocado mais um - ainda que diminuto - tijolo nessa fortificação que é, e deve ser, a ciência do direito levada à sério. 


\section{REFERÊNCIAS}

$\underline{\text { Bibliografia }}$

AlPA, Guido, Manuale di Diritto Privato, 5ª ed., Padova, CEDAM, 2007.

Alves, João Luiz, Código Civil, vol. 2, 2ª ed., São Paulo, Saraiva \& Cia, 1935.

Amaral, Francisco, Direito Civil - introdução, $7^{\mathrm{a}}$ ed., Rio de Janeiro, Renovar, 2008.

$\overline{170-178 .}$

, Negócio jurídico, in Enciclopédia Saraiva do Direito, vol. 54, São Paulo, 1977, pp.

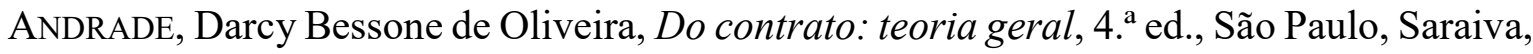
1997.

ANDRADE, Érico, O silêncio no ato e no negócio jurídico, in Revista Brasileira de Estudos Políticos, n.98, Belo Horizonte, jul./dez. 2008, pp. 99-118.

ANDRADE, Manuel A. Domingues de, Teoria geral da relação jurídica (vol. II), Coimbra, Almedina, 2003.

ANDRADE, Wendell Santiago, O papel jurídico do silêncio no novo direito civil (por uma teoria do silêncio vontade), in Revista Jurídica, v.52, n. 316, Porto Alegre, fev. 2004. p. 70 81.

Ascensão, José de Oliveira, Direito civil: teoria geral, Coimbra, Coimbra Editora, 1999.

AuBry, Charles Marie Barbe Antoine, e RAU, C., Cours de droit civil français, v. 4, 5. ed., Paris, Marchal et Billard, 1902.

AzEVEDo, Antonio Junqueira de, Insuficiências, deficiências e desatualização do projeto de Código Civil na questão da boa-fé objetiva nos contratos, in Revistra Trimestral de Direito Civil, v.1, São Paulo, jan. 2000, pp. 3-12.

, Negócio jurídico: existência, validade e eficácia, 4a ed., São Paulo, Saraiva, 2002.

BaUdRY-LaCANTINIÈRIE, Marie Paul Gabriel, et BARDE, L., Traité theorique et pratique de droit civil: des obligations, v. 1, Paris, Sirey, 1906.

BITTAR, Carlos Alberto, Silêncio (Efeitos jurídicos), in Enciclopédia Saraiva do Direito, vol. 69, São Paulo, 1977, pp. 40-43.

Bonfante, Pietro, Il Silenzio nella Conclusione dei Contratti, in Rivista de Diritto Commerciale, v. IV, parte II, 1906, pp. 222-230. 
, Instituzioni di diritto romano, 10. ${ }^{a}$ ed., Torino, G. Giappichelli, 1946.

Carvalho, E. V. de Miranda, A função do silêncio na formação e na dissolução dos contractos, in Revista dos Tribunais, a. 25, v. 100, São Paulo, abr. 1936, pp. 339-349.

Carvalho, João Procópio de, Locação de serviço, in Revista da Faculdade de Direito da Universidade de Minas Gerais, out. 1959, pp. 161-166.

Carvalho Santos, João Manoel de, Código Civil Brasileiro Interpretado, v. 3, $2^{\mathrm{a}}$ ed., Rio de Janeiro, Freitas Bastos, 1937.

Coelho da Rocha, M. A., Instituições de Direito Civil Portuguez, v.1, $3^{\mathrm{a}}$ ed., Coimbra, 1852 .

Colin, Ambroise, et CAPITAnt, Henri, Cours élémentaire de droit civil français, v. 2, Paris, Dalloz, 1939.

Costa, Philomeno J. da, O silêncio nos negócios jurídicos, in Revista dos Tribunais, a.50, v. 315, São Paulo, jan. 1962, pp. 495-519.

Couto e Silva, Clóvis Veríssimo do, A obrigação como processo, Rio de Janeiro, FGV, 2007.

, O princípio da boa-fé no Direito Brasileiro e Português, in Estudos de direito civil

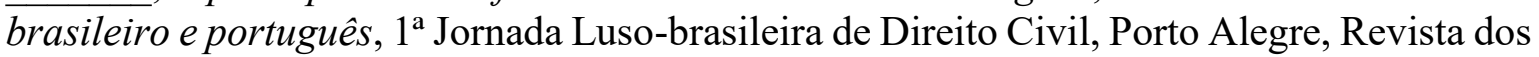
Tribunais, 1980, pp. 43-72.

CunHA, Abelmar Ribeiro da, Da declaração ou manifestação de vontade nos contratos: o consentimento, in Revista Forense, n.165, mai/jun 1956, pp. 45-53.

Demogue, René, Traité des obligations en géneral, vol. 1, Paris, Rousseau, 1923.

, Traité des obligations en géneral, vol. 2, Paris, Rousseau, 1923.

ESPÍNOLA, Eduardo, Systema do direito civil brasileiro, v. 1, $3^{\mathrm{a}}$ ed., Rio de Janeiro, Francisco Alves, 1938.

FARIA, Antonio Bento de, Código comercial brasileiro comentado, v.1/2, Rio de Janeiro, Jacinto Ribeiro dos Santos, 1929.

FLuME, Werner, Rechtsgeschäft, 1992, trad. esp. José María Miquel González e Esther Gómez Calle, El negocio jurídico, Madri, Fundación Cultural del Notariado, 1998.

FRADERA, Véra Jacob de, $O$ valor do silêncio no novo código civil, in Aspectos controvertidos do novo código civil, AlviM, Arruda; CÉSAR, Joaquim P. de Cerqueira; RosAs, Roberto (Org.), São Paulo, Revista dos Tribunais, 2003. p. 569-582.

FrançA, Rubens Limongi, Ato jurídico, in Enciclopédia Saraiva do Direito, vol. 9, São Paulo, Saraiva, 1977, pp. 20-27. 
GaBBA, Carlo Francesco, Questioni di Diritto Civile, 2 vols., 2. ${ }^{\text {a }}$ ed., Torino, Fratelli Bocca, 1909.

Gagliano, Pablo Stolze; e Pamplona Filho, Rodolfo, Novo Curso de Direito Civil, vol. I, $8^{\mathrm{a}}$ ed., São Paulo, Saraiva, 2006.

Giorgi, Giorgio, Teoria delle Obbligazioni nel diritto moderno italiano, vol. 3, $7^{\mathrm{a}}$ ed., Firenze, Fratelli Cammelli, 1907.

Gomes, Orlando, Autonomia Privada, in Enciclopédia Saraiva do Direito, vol. 9, São Paulo, 1977, pp. 258-260.

, Introdução ao direito civil, 20ª ed., Rio de Janeiro, Forense, 2010.

GonÇALves, Carlos Roberto, Direito civil brasileiro (vol. 1 - parte geral), $11^{\mathrm{a}}$ ed., São Paulo, Saraiva, 2013.

Houaiss, Antônio; e ViLlar, Mauro de Salles, Dicionário Houaiss da língua portuguesa, $1^{\mathrm{a}}$ ed., Rio de Janeiro, Objetiva, 2009

HuC, Téophile, Commentaire théorique et pratique du Code Civil, t. 7, Paris, F. Pichon, 1894.

JoSSERAND, Louis, Cours de droit civil positif français, v. 2, $3^{\mathrm{a}}$ ed., Paris, Recueil Sirey, 1939.

Laurent, François, Principes de Droit Civil Français, t. 15. 5a ed., Bruxelas, BruylantChristophe, 1893.

1893.

, Principes de Droit Civil Français, t. 32, 5ª ed., Bruxelas, Bruylant-Christophe,

LENEL, Otto, Palingenesia Iuris Civilis, volumen primum, Lipsiae, 1889.

LoBo, Jorge, Efeitos do silencio e da ratificação no contrato de mandato civil ou mercantil, in Revista de Direito Mercantil, Industrial, Econômico e Financeiro, v. 37, n. 114, São Paulo, abr./jun. 1999, pp. 68-72.

LoPez, Tereza Ancona, Silêncio (Direito civil), in Enciclopédia Saraiva do Direito, vol. 69, São Paulo, 1977, pp. 34-40.

Lotufo, Renan, Código Civil comentado - parte geral (arts. $1^{\circ}$ a 232 - v.1), $2^{\text {a }}$ ed., São Paulo, Saraiva, 2004.

LOURENCO, Rocha, Silêncio na formação dos contractos: regra moral e jurídica, Rio de Janeiro, Litho-Typographia Fluminense, 1940.

Ludwig, Marcos de Campos, Usos e costumes no processo obrigacional: fundamentos e aplicação em face do novo código civil, São Paulo, Revista dos Tribunais, 2005. 
LUMIA, Giuseppe, Lineamenti e ideologia del diritto, $3^{\mathrm{a}}$ ed., Milano, Giuffrè, 1981, pp. 102123, trad. pt. Alcides Tomasetti Júnior, 1999.

Macedo, Silvio de, Das formas do silêncio jurídico, in Revista de Direito Civil, Imobiliário, Agrário e Empresarial, v. 6, n. 19, São Paulo, jan./mar., 1982, p.76-79.

MARCHI, Eduardo C. Silveira, Guia de metodologia jurídica: teses, monografias e artigos, $2^{a}$ ed., São Paulo, Saraiva, 2009

Martins-Costa, Judith Hofmeister, A Boa-Fé no Direito Privado, São Paulo, Revista dos Tribunais, 1999.

, As cláusulas gerais como fatores de flexibilização do sistema, in Revista de

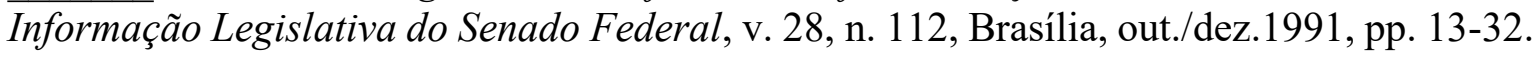
, Método da concreção e a interpretação dos contratos: primeiras notas de uma leitura suscitada pelo Código Civil, in Questões controvertidas no direito das obrigações e nos contratos (vol. 4), Delgado, Mário Luiz; Alves, Jones Figueiredo (Org.), São Paulo, Método, 2005.

Mattia, Fábio Maria de, Ato jurídico em sentido estrito e negócio jurídico, in Enciclopédia Saraiva do Direito, vol. 9, São Paulo, Saraiva, 1977, pp. 36-50.

MeIRELES, Rose Melo Vencelau, O negócio jurídico e suas modalidades, in A parte geral do novo código civil, coord. Gustavo Tepedino, $3^{\text {a }}$ ed., Rio de Janeiro, Renovar, 2007, pp.181-230.

Mello, José Baptista de, O silencio no direito, in Revista dos Tribunais, a. 26, v. 105, São Paulo, jan. 1937, pp. 3-20.

Mello, Marcos Bernardes de, Teoria do Fato Jurídico, $3^{\text {a }}$ ed., São Paulo, Saraiva, 1988. , Teoria do Fato Jurídico: Plano da Existência, 16ª ed., São Paulo, Saraiva, 2010.

MendonçA, Manoel Ignacio Carvalho de, Doutrina e Prática das Obrigações, t. 2, $4^{\mathrm{a}}$ ed., Rio de Janeiro, Revista Forense, 1956.

Menezes Cordeiro, António Manuel da Rocha, Da boa fé no direito civil, Lisboa, Almedina, 2011. Almedina, 2005.

, Tratado de Direito Civil português (vol. I - parte geral). $3^{\mathrm{a}}$ ed., Coimbra,

Moncada, Luís S. Cabral de, Lições de Direito Civil: parte geral, v. 2, Coimbra, Atlantida, 1932.

Monteiro, Washington de Barros Monteiro e PINTO, Ana Cristina de Barros Monteira França, Curso de direito civil (vol. 1 - parte geral), 42ª ed., São Paulo, Saraiva, 2009. 
MoreIRA Alves, José Carlos, Distinção entre os atos jurídicos negociais e os atos jurídicos não-negociais, in Revista da Academia Brasileira de Letras Jurídicas, disponível online, $\mathrm{n}^{\circ}$ 10, 1996, pp. 170-189, [30-11-2015].

, O novo Código Civil brasileiro: principais inovações na disciplina do negócio jurídico e suas bases romanísticas, in Rivista Internazionale di Scienze Giuridiche e Tradizione Romana, disponível online, n. . 5, 2006 [10-06-2014].

Moser, Luiz Gustavo Meira, A aceitação da cláusula compromissória pelo silêncio, à luz da conduta negocial das partes: a cláusula geral do art. 111 do Código Civil brasileiro, in Revista de Direito Mercantil Industrial, Econômico e Financeiro, v. 49, n. 153/154, São Paulo, jan./jul. 2010, pp. 105-115.

PEREIRA, Caio Mário da Silva, Instituições de direito civil (vol. 1 - introdução ao direito civil, teoria geral de direito civil), 24 ${ }^{\mathrm{a}}$ ed., Rio de Janeiro, Forense, 2011.

2003.

, Instituições de direito civil (vol. 3 - contratos), $11^{\mathrm{a}}$ ed., Rio de Janeiro, Forense, , Instituições de direito civil (vol. 6 - direito das sucessões), 16 a ed., Rio de Janeiro, Forense, 2008.

PINTO, Paulo Cardoso Correia da Motta, Declaração tácita e comportamento concludente no negócio jurídico, Coimbra, Almedina, 1995.

Planiol, Marcel; RIPERT, Georges; e EsMeIn, Paul, Traité pratique de droit civil français: obligations première partie, t. VI, 2a ed., Paris, LGDJ, 1952.

Pontes de Miranda, Francisco Cavalcanti, Tratado de direito privado (tomo I), $2^{\mathrm{a}}$ ed., Rio de Janeiro, Borsoi, 1962.

, Tratado de direito privado (tomo II), São Paulo, Revista dos Tribunais, 2013.

, Tratado de direito privado (tomo V), São Paulo, Revista dos Tribunais, 2012.

, Tratado de direito privado (tomo VIII), $3^{\mathrm{a}}$ ed., Rio de Janeiro, Borsoi, 1971.

, Tratado de direito privado (tomo XXXVIII), 2ª ed., Rio de Janeiro, Borsoi, 1962.

, Tratado de direito privado (tomo LV), São Paulo, Revista dos Tribunais, 2012.

Popesco-RAmniceano, René, Le Silence Créateur d'Obligations et l'Abus Du Droit, in Révue Trimestrielle de Droit Civil, t. XXIX, 1930, pp. 999-1009.

RÁo, Vicente, $O$ ato jurídico, $1^{\text {a }}$ ed., São Paulo, Max Limonad, 1961.

RIBAS, Antônio Joaquim, Direito civil brasileiro, Rio de Janeiro, Editora Rio, 1977. 
RODRIGUES, Jose Martins, Elementos geradores do vínculo obrigacional e efeitos jurídicos do silêncio, Dissertação para o concurso à cátedra de direito civil na Faculdade de Direito do Ceará, Fortaleza, 1934.

Rodrigues, Silvio, Direito Civil (vol. 1), 34ª ed., São Paulo, Saraiva, 2007.

Roppo, Enzo, Il Contratto, trad. pt. Ana Coimbra e M. Januário C. Gomes, O contrato, Coimbra, Almedina, 2009.

Ruggiero, Roberto de, Istituzioni di Diritto Civile, trad. pt. Paolo Capitanio, Instituições de Direito Civil, vol. I, $2^{\mathrm{a}}$ ed., Campinas, Bookseller, 2005.

SAlEILles, Raymond, De la déclaration de volonté: contribution à l'étude de l'acte juridique dans le code civil allemand (art. 116 à 144), Paris, R Pichon R Durand-Auzias, 1929.

SAVIGNY, F. K., System des heutigen römischen Rechts", trad. de Vittorio Scialoja, Sistema del Diritto Romano Attuale, v. 3, Torino, Unione Tipografico, 1886.

Serpa Lopes, Miguel Maria de, Curso de Direito Civil (vol. 1), $8^{\mathrm{a}}$ ed., Rio de Janeiro, Freitas Bastos, 1996.

1935.

, O silêncio como manifestação de vontade: obrigações em geral, Rio de Janeiro,

TALAVERA, Glauber Moreno, As concepções artificiais e o silêncio do novo Código Civil, in IOB-Repertório de Jurisprudência: civil, processual, penal e comercial, n. 17, São Paulo, set. 2002, pp. 473-471.

TARTUCE, Flávio, Manual de Direito Civil, 6a ed., São Paulo, Método, 2016.

Tepedino, Gustavo, Barboza, Heloísa Helena, Moraes, Maria Celina Bodin de, Código Civil interpretado conforme a Constituição da República - parte geral e obrigações (arts. $1^{\circ}$ a 420 - v.1), $2^{\mathrm{a}}$ ed., Rio de Janeiro, Renovar, 2007.

Tutikian, Priscila David Sansone, O silêncio na formação contratual: elementos qualificadores de sua valoração declarativa, Dissertação de mestrado apresentada à Faculdade de Direito da Universidade Federal do Rio Grande do Sul, Porto Alegre, 2007.

VALlAR, Sandrine, Silence et contrats em droit romain, in Révue des contrats, jul. 2014, pp. 288-295.

Venosa, Silvio de Salvo, Direito Civil (parte geral), 9ª ed., São Paulo, Atlas, 2009.

WALD, Arnoldo, Direito civil: introdução e parte geral, 9ª ed., São Paulo, Saraiva, 2002. 
$\underline{\text { Índice de Jurisprudência }}$

STJ: Recurso Especial n. ${ }^{\circ}$ 722.469-PB

Recurso Especial n..$^{\circ}$ 1.306.367-SP

TJ-SP: Apelação nº 0009912-95.2011.8.26.0176

Apelação no 0079347-96.2011.8.26.0002

Apelação no 0174843-57.2008.8.26.0100

Agravo de instrumento $\mathrm{n}^{\mathrm{o}}$ 0108050-09.2012.8.26.0000

Apelação $n^{\circ}$ 0122451-38.2011.8.26.0100

Apelação $n^{\circ}$ 0004208-05.2009.8.26.0360

Apelação no 992.06.014569-1

Apelação $n^{\circ}$ 0004838-46.2007.8.26.0323

Apelação $n^{0}$ 991.08.012028-3

Apelação $\mathrm{n}^{0}$ 0042082-97.2009.8.26.0562

Apelação $n^{\circ}$ 9192449-51.2008.8.26.0000

Apelação $n^{\circ}$ 9120397-28.2006.8.26.0000

Apelação $n^{\circ}$ 9132734-78.2008.8.26.0000

Apelação no 0211234-74.2009.8.26.0100

Apelação no 0331681-66.2010.8.26.0000

TJ-RS: Apelação no 70047806849

Apelação no 70045918927

Recurso Inominado $\mathrm{n}^{\mathrm{o}} 71001022136$

Apelação no 70061107538

TJ-PE: Agravo legal no 0253336-6/01

Apelação no 0353851-0

Apelação nº 0275195-9 